\title{
Facilitators and Barriers to Cervical Cancer Screening among Female Undergraduate Students of Makerere University
}

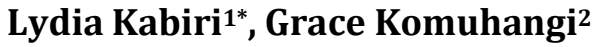 \\ ${ }^{1}$ Department of Nursing, College of Health Sciences, Makerere University, Kampala, Uganda \\ ${ }^{2}$ School of Nursing and Midwifery, Clarke International University, Kampala, Uganda \\ Email: *kabdia4@gmail.com
}

How to cite this paper: Kabiri, L. and Komuhangi, G. (2021) Facilitators and Barriers to Cervical Cancer Screening among Female Undergraduate Students of Makerere University. Open Journal of Nursing, 11, 620-641. https://doi.org/10.4236/ojn.2021.117053

Received: October 27, 2019

Accepted: July 26, 2021

Published: July 29, 2021

Copyright $\odot 2021$ by author(s) and Scientific Research Publishing Inc. This work is licensed under the Creative Commons Attribution International License (CC BY 4.0).

http://creativecommons.org/licenses/by/4.0/ (c) (i) Open Access

\begin{abstract}
There is a higher Human Papilloma Virus peak prevalence in younger women (18 - 25 years) of university age. The undergraduate university students are more at a risk of acquiring cervical cancer because they are at the stage of exploring which predisposes them to risky behavior like early sexual intercourse and multiple sexual partners among others. This creates a need for cervical cancer screening in the population. The facilitators and barriers to cervical cancer screening have been studied in the Ugandan general population but little is known among University students which this study is taking interest. Objective: This study is aimed at determining the facilitators, barriers and background factors associated to cervical cancer screening among female undergraduate students in Makerere University. Methods: Four hundred twenty-two (422) female undergraduate students of Makerere University who fit the eligibility criteria were recruited in this descriptive cross-sectional quantitative study. A self-administered semi structured questionnaire was administered to these participants chosen by convenient sampling. Data collected was analyzed using SPSS version 23 software and logistic regression models was used. Results: Less than a half of (21.1\%) of the participants had ever screened for cervical cancer. At multivariate analysis, only year of study and married status were associated to cervical cancer screening with a P-values were of (0.015) and (0.001) with a (1.173 - 4.261) and (1.594 - 6.130) 95\% CI respectively. The facilitators agreed upon by participants included: Access to free cervical cancer screening services, adequate knowledge about cervical cancer screening and advice from a friend, family or physician among others. The reported barriers to screening were fear of bad result, low risk perception and fear of embarrassment among others. Conclusions and Recommendations: Among the female undergraduate students of Makerere
\end{abstract}


University, only $21.1 \%$ had screened for cervical cancer. Therefore, there is a critical need for university based cancer education campaign on cervical cancer and the benefits of screening. Screening services should be integrated into the existing university medical services.

\section{Keywords}

Facilitators, Barriers, Cervical Cancer Screening, Female Undergraduate Students, Makerere University

\section{Introduction}

Cervical cancer is defined as an outgrowth of cells in the lining of the cervix [1] It's the fourth most frequent cancer worldwide with an estimated 570,000 new cases equivalent to $6.6 \%$ of all the female cancers. Basically, $70 \%$ of the cervical cancers and precancerous cervical lesions are caused by Human Papillomavirus (HPV) types 16 and 18 (WHO, 2018).

In East Africa, the annual number of new cases are 45,707 with a crude incidence rate of 25.8 and an age standardized incidence rate of approximately 42.7 per 100,000 women [1]. With over 3915 new cases diagnosed annually, cervical cancer is most common female diagnosed cancer in Uganda among women aged 15 - 44 years [2]. The national cervical cancer crude incidence rate of 22.0, age standardized incidence rate of $44.4 \%$ and annual mortality rate of up to 2275 . The highest cervical cancer incidence rates are affiliated to the $33.6 \% \mathrm{HPV}$ prevalence among the Ugandan women and low screening uptake [3].

Around $3.6 \%$ of feminine Ugandan population are estimated to harbor cervical HPV-16/18 infection at a time, and $57 \%$ of invasive cervical cancers are attributed to HPVs 16 or 18 [4]. The risk factors for HPV persistence and development of cervical cancer include; early first sexual intercourse ( $<18$ years), multiple sexual partners, sexually transmitted infection history, immune suppression e.g. HIV infected individuals are at higher risk of HPV infection [5]. Prevention of cervical cancer relies on population screening methods like Visual Inspection with Acetic Acid (VIA) and Papanicolaou smear test for the early detection and appropriate management of its precursor lesions [6].

The relatively increased sexual engagement of female Makerere university students of up to $62.1 \%$ and their low condom use of only $34.5 \%$ exposes them to HPV and cervical cancer [7]. This behavior only leaves regular cervical cancer screening of these young women as the only reliable way to confer an overall public health benefit of curbing down the mortality of the disease and should thus be encouraged.

Despite the benefit of cervical cancer screening many female African university students have not taken the initiative to undergo it. In studies carried out, only $27.5 \%$ and $15 \%$ of the university students in Botswana and South Africa respectively had ever screened for cervical cancer [8]. 
In Uganda however, studies have assessed the uptake of cervical cancer screening but there's paucity of data on cervical cancer screening among female university students. Yet, considering the few numbers of young women who have taken up cervical cancer screening it is relevant to comprehend the facilitators and barriers to screening even in learned populations like university students.

Cervical cancer is the most frequent cancer among Ugandan women aged 15 to 44 years [9] [10] [11]. Current estimates in the country indicate that every year 6413 women are diagnosed with cervical cancer and 4301 die from the disease [1] [9]. Screening for cervical cancer is greatly relevant as it allows for early diagnosis and management thus reducing the mortality rates greatly [12]. Despite the benefits of cervical cancer screening, its uptake among women in Uganda is still very low only $4.2 \%$ of women having screened for cervical cancer [2] and a meagre 7\% of those screened in the central region screen [13].

More than 6 in 10 female undergraduate University students engage sexual activity which is accompanied by related risky sexual behavior like having multiple sexual partners among others [9]. This, together with their low cervical cancer screening uptake has increased the risk of exposure to the disease [14].

Low prevalence of cervical cancer screening has increased the need to create and implement resolutions so as to foster the practice and relieve this global public health problem. These approaches should be based on an understanding of the magnitude of facilitators and barriers to cervical cancer screening among young literate people such as female undergraduate students of Makerere University so as to inform policy.

\section{Methods}

\subsection{Study Design}

A descriptive cross-sectional study design involving a quantitative method was used to collect data in a period of six months between August 2018 and February 2019. This involved capturing information based on data collection at a specific point in time which was appropriate for describing the phenomenon. This method is relatively cheap, requires less time and many findings and outcomes can be analyzed to create new theories. The quantitative approach is objective and reliable in research.

\subsection{Study Site}

This study was conducted at Makerere University in Kampala. This is Uganda's largest University with an average population of over 36,947 registered students for undergraduate level with a $45 \%(16,549)$ proportion being females. The university ranks among the top 4 universities and third oldest institute of higher learning in Africa. The mission of this University is to provide innovative teaching, learning, research and services responsive to both National and Global needs. The 350 -acre main campus is located on Makerere hill $5 \mathrm{~km}$ from the city 
center. At the undergraduate level the university offers up to 134 Bachelors' programs with 9 colleges of study. The university has three halls of attachments for female students which include Mary Stuart, Africa and Complex halls. Some students are residing in these halls of residence while others are just attached and reside elsewhere (Mak Fact Book-Special Edition, 2015-2016).

\subsection{Study Population}

The target population of this study were the female undergraduate students at Makerere University. The study participants were accessed at their halls of residence and dining rooms during lunch break and evening time. The participants were briefed on the purpose of the study as well as the issues of confidentiality and consent.

\subsection{Inclusion Criteria}

To be eligible for this study, participants had to meet the following requirements:

- Female Undergraduate students because majority are in the risky age group.

- Aged 18 years and above and present at the time of the study.

- Attached to any of female undergraduate halls of residence.

\subsection{Exclusion Criteria}

The participant who was not allowed to participate in this research included;

- Females with a history of a hysterectomy.

- Females already undergoing treatment of precancerous lesions of the cervix were not being legible.

- The blind students because they were not able to read the questionnaire.

\subsection{Sampling Procedure}

The sample size was calculated from Kish Leslie (1965) formula for calculating sample size which is;

$$
n=\frac{z^{2} p(1-P)}{d^{2}}
$$

where $n$-estimated sample size;

$Z$-Standard normal value corresponding to the level of confidence (1.96);

$P$-estimated proportion of the study population with variable of interest (0.5) this is because no study has been done to assess the proportions of females that have screened for cervical cancer in Uganda;

$d$-degree of precision (0.05).

By taking 95\% confidence interval

$$
n=\frac{1.96 \times 20.5 \times(1-0.5)}{0.05^{2}}
$$

$n=384$. Substituting the above formula therefore the sample size was 384 . 
Since the data collection tool was self-administered questionnaire, the number of participants was increased by $10 \%$ to cater for any questionnaires that may not be returned.

$$
n=384 \text { subjected to } 10 \% \text { increment } n=422 \text { participants. }
$$

\subsection{Definition and Measurement of Variables}

\section{Independent and Dependent Variables}

The independent variables included: the socio-demographic factors like age, marital status, religion, tribe, address and reproductive factors like (family planning use, sexual activity, age of first sexual intercourse, number of sexual partners, awareness of cervical cancer and screening, prior contact with disease).

Facilitators include access to cervical cancer screening services, affordability of screening services, availability of free cervical cancer screening centers, gender sensitivity cervical cancer screening services, recommendation by a physician, family member, friend, prior direct or indirect contact with the disease, youth friendly cervical cancer screening services, the health facility level factors are access to screening services, hospital waiting time, affordability of screening, gender sensitivity, youth friendly services, knowledge of individual HIV status. Barriers for cervical cancer screening include individual; fear of outcome results, inadequate knowledge about cervical cancer screening, anticipation of pain and discomfort during the procedure, low risk perception.

University factors: busy university schedule, lack of services at screening services at the university hospital.

Health facility factors: screening by a male physician, financial constraints, discrimination at hospitals, long waiting hours, poor quality services, lack of privacy, fear of hospital acquired infections. The dependent variable in this study was cervical cancer screening.

\subsection{Data Collection Tools}

In this study, the researcher administered a semi-structured self-administered questionnaire to eligible participants. The questionnaire was made of 63 questions in three sections aimed to determine the facilitators, barriers and background factors associated to cervical cancer screening among female undergraduate students in Makerere University. The first section assessed the background factors which consisted of socio-demographic factors Age, marital status, individual factors like family planning use, sexual activity and also assessed the proportions of the students that have ever screened for cervical cancer. The second and third sections of the questionnaire were adopted from a tool used in a study [15]. This tool was modified to suit the interest of this particular study. The second section consisted of questions that assessed the facilitators like access to cervical cancer screening services, need for maintaining good health, affordability of cervical cancer screening and gender sensitive services and others. The third section consisted of questions that assessed the barriers to cervical cancer screening like financial constraints, low risk perception, limited time to go for 
screening due to busy University schedule, long waiting hours at the University among others. Filling of the questionnaire took approximately 15 - 20 minutes.

\subsection{Data Collection Procedure}

After review and approval by IRB, the principal investigator introduced herself to the wardens of the different halls of residence and sought approval for data collection. The principal investigator then proceeds to collect the data. Participants were approached from the dining halls of the different halls of residents during lunch time break and also their residential rooms. The principal investigator waited with questionnaires at the entrance to the dining hall and rooms. She briefly introduced herself to the eligible research respondents then explained the aim of the study and obtained informed consent. The principal investigator handed over the self-administered semi structured questionnaire to the selected participant to fill it. Some of the participants who argued that they hadn't finished were allowed to stay with the questionnaires. The principal investigator then recorded the phone numbers and the room numbers of the eligible respondents so as to follow up and be able to collect the questionnaires. It's estimated that each participant took approximately 15 - 20 minutes to complete the questionnaires.

\subsection{Quality Control Measures}

The semi-structured questionnaire was pretested prior to data collection on 10 female Makerere University students to review and make adjustments accordingly. The data collection interviews were conducted only by the principal investigator to ensure accuracy of data collected. The questionnaires were also checked for completeness to ensure that the required data is collected. This was done on collection of the questionnaires from the respondents and before analysis. Data entry and analysis was carried out by the principal investigator with the aid of the supervisor to obtain accuracy and proper interpretation of findings.

\subsection{Data Management}

The questionnaire was collected from the selected research participants after being filled to assess for completeness. Of the 422 questionnaires distributed, only 355 were recovered from the respondents as some argued that they lost them and others just kept on promising to return them and never did. All the questionnaire was anonymous never contained the names but rather codes. The filled questionnaires were then kept under lock and key to maintain confidentiality and avoid losses of the respondent's information.

\subsection{Data Analysis}

Data were coded and then input into SPSS version 23 software, cleaned and categorized into meaningful units before analysis. At univariate analysis, mean, median, frequency tables and standard deviations of continuous variables were derived. At bivariate analysis level, chi square tests for the strength of association 
between the independent variables and cervical cancer screening will be carried out. The variables that were found statistically significant at bivariate analysis with a p-value of less or equal to 0.05 and those that were plausible were taken to logistic regression for further analysis after which the facilitators and barriers to cervical cancer screening were determined. These results were then presented in form of tables and a pie chart.

\subsection{Ethical Consideration}

The research proposal was presented to the department of nursing Makerere University then to the School of Health Sciences Institutional Review Board (SCHIRB) for ethical approval informed consent was sought and obtained from the study respondents after equipping them with all the information about the study. The consent forms were signed before filling in the questionnaires. The names of the study participants were not written to ensure confidentiality. The respondents were free to withdraw from the study at any time without penalty.

\section{Results}

\subsection{Socio-Demographic Characteristics of the Respondents}

Table 1 shows the basic socio-demographic characteristics of the study respondents $(\mathrm{N}=355)$ out of the 422 students who were enrolled in the study. Majority (60.6\%) of the participants were between twenty-one and twenty-five (21 - 25) years with most $(37.5 \%)$ of the respondents in their second year of study. More than half $(71 \%)$ of the respondents were from non-health related collages and only $29.0 \%$ were from colleges with health-related courses. Over $81 \%$ of the respondents were single and mostly (34.4) attached to Mary Stuart and Africa halls of residence.

Figure 1: The Pie Chart below indicates the prevalence of cervical cancer screening among female university students.

The details are summarized in Table 1.

\subsection{Reproductive Health Characteristics of the Study Participants}

Most (73\%) of the respondents had had sexual intercourse and of those $23.9 \%$ had their first sexual intercourse before 16 years of age (mean $=17.76, \mathrm{SD}=$ 1.814 , median $=17$ ). More than half of the respondents $(65.4 \%)$ had ever used family planning with the majority (25.4\%) having used contraceptive pill. Almost all (97.7\%) had heard about cervical cancer screening and their major information source was media. Nearly all the respondents (91.5\%) were willing to screen for cervical cancer in the future. The details are summarized in Table 2 below.

\subsection{Prevalence of Cervical Cancer Screening among the Female Undergraduate Students of Makerere University}

The proportion $(21.1 \%)$ of the female undergraduate students who have ever screened for cervical cancer and majority (78.9\%) who have never screened for cervical cancer. 
Table 1. Socio-demographic characteristics of the respondents.

\begin{tabular}{|c|c|c|c|}
\hline Variable & Categories & Frequency $(n=355)$ & Percentage (\%) \\
\hline \multirow[t]{3}{*}{ Age in years } & $17-20$ & 114 & 32.1 \\
\hline & $21-25$ & 215 & 60.6 \\
\hline & Above 25 & 26 & 7.3 \\
\hline \multirow[t]{3}{*}{ Marital status } & Single & 288 & 81.1 \\
\hline & Married & 64 & 18.0 \\
\hline & Separated & 3 & 0.8 \\
\hline \multirow[t]{3}{*}{ Religion } & Christian & 175 & 49.8 \\
\hline & Moslem & 129 & 36.3 \\
\hline & Others & 51 & 14.4 \\
\hline \multirow[t]{5}{*}{ Year of study } & Year 1 & 68 & 19.2 \\
\hline & Year 2 & 113 & 37.5 \\
\hline & Year 3 & 102 & 28.7 \\
\hline & Year 4 & 41 & 11.5 \\
\hline & Year 5 & 11 & 3.1 \\
\hline \multirow[t]{2}{*}{ Colleges } & College with health-related courses & 103 & 29 \\
\hline & $\begin{array}{l}\text { Colleges with non-health related } \\
\text { courses }\end{array}$ & 252 & 71 \\
\hline \multirow[t]{3}{*}{ Hall of resident } & Complex & 111 & 31.3 \\
\hline & Mary Stuart & 122 & 34.4 \\
\hline & Africa & 122 & 34.4 \\
\hline
\end{tabular}

\subsection{Bivariate Analysis of Socio-Demographic Characteristics That May Influence Cervical Cancer Screening}

The strength of association between the social-demographic characteristics and cervical cancer screening was done using Chi square tests. The only significant findings revealed were married $(\mathrm{OR}=0.173, \mathrm{CI} 0.096-0.312 \mathrm{P}$-value $<0.001)$ and year of study $\leq$ year $2(\mathrm{OR}=0.396, \mathrm{CI} 0.235-0.668 \mathrm{P}$-value $<0.001)$. The rest of the variables were not significantly associated with cervical cancer screening. The details are summarized in Table 3 below.

\subsection{Facilitators of Cervical Cancer Screening among the Students}

Regarding the facilitators to cervical cancer screening majority (89\%) of the participants needed to discover their health problems early, $69 \%$ of them think that having a regular cervical cancer screening test is the best way for it to be diagnosed early. Approximately $67 \%$ of the respondents believed that having regular 
Table 2. Distribution of respondents by their reproductive health characteristics.

\begin{tabular}{|c|c|c|c|}
\hline Variable & Categories & Frequency $(\mathrm{N}=365)$ & Percentage (\%) \\
\hline Ever had & Yes & 259 & 73 \\
\hline intercourse & No & 96 & 27 \\
\hline Age of first sexual & $\leq 16$ years & 85 & 23.9 \\
\hline intercourse & $>16$ years & 174 & 49 \\
\hline Current number of & One & 114 & 32.1 \\
\hline sexual partners & Multiple & 147 & 41.5 \\
\hline Family planning & Yes & 232 & 65.4 \\
\hline use & No & 123 & 34.6 \\
\hline Family planning & Condom & 74 & 20.8 \\
\hline \multirow[t]{4}{*}{ methods used } & Contraceptive pill & 90 & 25.4 \\
\hline & Intrauterine device & 22 & 6.2 \\
\hline & Implant & 24 & 6.8 \\
\hline & Depo injection & 23 & 6.5 \\
\hline Awareness of & Yes & 343 & 96.6 \\
\hline cervical cancer & No & 12 & 3.4 \\
\hline Awareness of & Yes & 347 & 97.7 \\
\hline Cervical cancer & No & 8 & 2.3 \\
\hline screening source of & Health practitioner & 81 & 22.8 \\
\hline \multirow[t]{4}{*}{ information } & Media & 114 & 32.1 \\
\hline & Friend & 81 & 22.8 \\
\hline & Family & 48 & 13.5 \\
\hline & lecturer & 25 & 7.0 \\
\hline Willingness to & Yes & 325 & 91.5 \\
\hline screen in the future & No & 30 & 8.5 \\
\hline
\end{tabular}

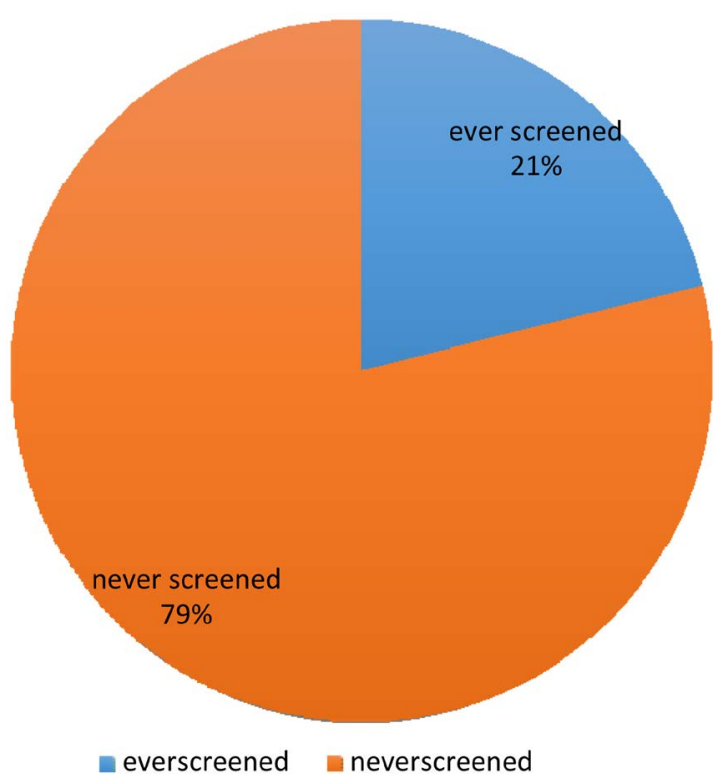

Figure 1. Prevalence of cervical cancer screening among female undergraduate students of Makerere University. 
Table 3. Association between the socio-demographics and cervical cancer screening.

\begin{tabular}{|c|c|c|c|c|c|}
\hline \multirow[t]{2}{*}{ Variable } & $\begin{array}{c}\text { Ever } \\
\text { screened for }\end{array}$ & $\begin{array}{c}\text { Never } \\
\text { screened for }\end{array}$ & \multirow[t]{2}{*}{ OR } & \multirow[t]{2}{*}{$95 \%$ CI } & \multirow[t]{2}{*}{ P-value } \\
\hline & $\mathrm{CaCx}(\%)$ & $\mathrm{CaCx}(\%)$ & & & \\
\hline \multicolumn{6}{|l|}{ Marital status } \\
\hline Married & $32(50.0 \%)$ & $248(85.2 \%)$ & 0.173 & $0.096-0.312$ & $<0.001^{*}$ \\
\hline Single & $43(14.8 \%)$ & $32(50.0 \%)$ & & & \\
\hline \multicolumn{6}{|l|}{ Religion } \\
\hline Christian & $39(22.3 \%)$ & $136(77.7 \%)$ & 1.147 & $0.689-1.910$ & 0.598 \\
\hline Non-Christian & $36(20.0 \%)$ & $144(80 \%)$ & & & \\
\hline \multicolumn{6}{|l|}{ Year of study } \\
\hline$\leq$ Year 2 & $29(14.4 \%)$ & $172(85.6 \%)$ & 0.396 & $0.235-0.668$ & $<0.001^{*}$ \\
\hline$>$ Year 2 & $46(29.9 \%)$ & $108(70.1 \%)$ & & & \\
\hline \multicolumn{6}{|l|}{ Colleges } \\
\hline Health-related & $24(23.3 \%)$ & 79 (76.7\%) & 1.917 & $0.690-2.076$ & 0.521 \\
\hline \multicolumn{6}{|l|}{ courses } \\
\hline Non-health & $51(20.2 \%)$ & $201(79.8 \%)$ & & & \\
\hline related courses & & & & & \\
\hline
\end{tabular}

*Significant findings.

cervical cancer screening test will help find changes to the cervix before they turn into a cancer, that if cervical cancer is found at a regular screening test then treatment won't be difficult. The details are summarized in Table 4 below.

\subsection{Barriers to Cervical Cancer Screening among the Participants}

Among the two hundred eighty participants that hadn't screened for cervical cancer the following were the barriers they had experienced. Most (81\%) were afraid of undergoing cervical cancer screening for fear of a bad result and 57\% believed that if there is cervical cancer development, having a screening test cannot prevent it. Approximately $80 \%$ reported that there were no screening services at the university hospital $40 \%$ agreed that the health professionals who do the cervical cancer screening test are very rude to women. The details are in Table 5 below.

\subsection{Bivariate Analysis for Reproductive Health Characteristics}

Chi square tests were used to demonstrate the strength of associations between reproductive health characteristics and cervical cancer screening. The significant findings included ever had sexual intercourse, Yes $(\mathrm{OR}=11.936, \mathrm{CI} 3.663$ 38.898), current number of sexual partners; One (OR $=0.490$, CI $0.277-0.868)$, 
Table 4. Distribution of the facilitators for cervical cancer screening among the study participants.

\begin{tabular}{|c|c|c|}
\hline $\begin{array}{l}\text { Variables; for only those that have } \\
\text { ever screened for cervical cancer }\end{array}$ & frequency & Percentage \\
\hline$(\mathrm{N}=75)$ & & (\%) \\
\hline I need to discover my health problems early & 67 & 89 \\
\hline Maintaining good health is important to me & 48 & 64 \\
\hline $\begin{array}{l}\text { Having regular cervical cancer screening test will help find } \\
\text { changes to the cervix before they turn into a cancer }\end{array}$ & 50 & 67 \\
\hline $\begin{array}{l}\text { If cervical cancer is found at a regular screening test then } \\
\text { treatment won't be difficult }\end{array}$ & 50 & 67 \\
\hline $\begin{array}{l}\text { I think that having a regular screening test is the best way } \\
\text { for it to be diagnosed early }\end{array}$ & 52 & 69 \\
\hline $\begin{array}{l}\text { Having regular screening tests will decrease the chances of } \\
\text { dying of cervical cancer }\end{array}$ & 49 & 65 \\
\hline I have regular checkups even when I am not screening & 48 & 64 \\
\hline I have access to free cervical cancer screening services & 46 & 61 \\
\hline I can afford the cervical cancer screening services & 48 & 64 \\
\hline $\begin{array}{l}\text { I got advice about cervical cancer screening from } \\
\text { my friend, family or physician. }\end{array}$ & 48 & 64 \\
\hline I have adequate knowledge about cervical cancer screening & 47 & 63 \\
\hline $\begin{array}{l}\text { I feel that the available cervical cancer screening } \\
\text { services are youth friendly }\end{array}$ & 44 & 59 \\
\hline $\begin{array}{l}\text { I feel that the available cervical cancer screening } \\
\text { services are gender sensitive. }\end{array}$ & 35 & 47 \\
\hline
\end{tabular}

Family planning use; Yes (OR $=8.255 \mathrm{CI} 3.467$ - 19.651) Willingness to screen in the future; Yes ( $\mathrm{OR}=0.308 \mathrm{CI} 0.142-0.668)$. The rest of the variables were not significantly associated to cervical cancer screening. The details are summarized in Table 6 below.

\subsection{Multivariate Analysis of the Socio-Demographic and Reproductive Health Characteristics that Influence Cervical Cancer Screening}

In Table 7 below, the variables that were found statistically significant at bivariate analysis and those that were plausible were taken to logistic regression for further analysis. The variables that were found significant included; marital status married $(\mathrm{OR}=3.126, \mathrm{CI} 1.594-6.130)$ and year of study $\leq$ year $2(\mathrm{OR}=2.235 \mathrm{CI} 1.173-$ 4.261). The other variables were not found significant for multivariate analysis. 
Table 5. Distribution of the barriers to cervical cancer screening among the participants.

\begin{tabular}{ccc}
\hline Variables only those who have never & Frequency & $\begin{array}{c}\text { Percentage } \\
\text { screened for cervical cancer }(\mathrm{N}=280)\end{array}$ \\
\hline
\end{tabular}

\section{Individual factors}

I am afraid of undergoing cervical cancer screening for fear of a bad result.

I am afraid to have cervical cancer screening because

I don't know what will happen

I am too young to have a test regularly

I don't know where to go for cervical cancer screening

I don't have the finances to go for cervical cancer screening.

I feel I am at a low risk of getting cervical cancer

I am ashamed to lie on a gynecological table for the cervical cancer screening test

I feel ashamed being screened by a male physician.

I think that the cervical cancer screening test if very painful

Cervical cancer screening is for only married people

I neglect or I can't remember to have a regular test

I have other problems in my life more important than a cervical cancer screening test like tuition, course work

If there is cervical cancer development, having a screening test cannot prevent it

My sexual partner doesn't want me to screen for cervical cancer

I use condoms every time I engage in sex. So I think I am protected

\section{University factors}

I have limited time to go for cervical cancer screening due to the busy university schedule.

There are no screening services at the university hospital

No health facility close to the university offers cervical cancer screening services

The university health department does not inform us on screening services and where to find them

\section{Health facility related factors}

Health professionals who do the cervical cancer screening test are very rude to women.

There are long waiting hours at cervical cancer screening centers.

I fear that I may get hospital acquired infections during cervical cancer screening. screening at the hospital

Sometimes the health professionals who offer the services are busy with other activities

Sometimes the reagents used in the screening are out of stock so the health workers give me another date which is not in line with my personal schedule. 
Table 6. Association of reproductive health characteristics and cervical cancer screening.

\begin{tabular}{|c|c|c|c|c|c|}
\hline \multirow[t]{2}{*}{ Variable } & $\begin{array}{c}\text { Ever } \\
\text { screened for }\end{array}$ & $\begin{array}{c}\text { Never } \\
\text { screened for }\end{array}$ & \multirow[t]{2}{*}{ O.R } & \multirow[t]{2}{*}{$95 \% \mathrm{CI}$} & \multirow[t]{2}{*}{ P-value } \\
\hline & $\mathrm{CaCx}(\%)$ & $\mathrm{CaCx}(\%)$ & & & \\
\hline \multicolumn{6}{|l|}{ Ever had sexual intercourse } \\
\hline Yes & $72(27.8 \%)$ & $187(72.2 \%)$ & 11.936 & $3.663-38.898$ & $<0.001^{*}$ \\
\hline No & $3(3.1 \%)$ & $93(96.9 \%)$ & & & \\
\hline \multicolumn{6}{|l|}{ Age of first sexual intercourse } \\
\hline$\leq 16$ years & $28(32.9 \%)$ & $57(67.1 \%)$ & 1.451 & $0.823-2.559$ & 0.197 \\
\hline $\begin{array}{l}>16 \text { years Current sexual } \\
\text { partners }\end{array}$ & $44(25.3 \%)$ & $130(74.7 \%)$ & & & \\
\hline One & $23(20.2 \%)$ & $91(79.8 \%)$ & 0.490 & $0.277-0.868$ & $0.013^{*}$ \\
\hline multiple Family planning use & $50(34.0 \%)$ & $97(66.0 \%)$ & & & \\
\hline Yes & $69(29.7 \%)$ & $163(70.3 \%)$ & 8.255 & $3.467-19.651$ & $<0.001$ \\
\hline $\begin{array}{l}\text { No Willingness to screen in } \\
\text { the future }\end{array}$ & $6(4.9 \%)$ & $117(95.1 \%)$ & & & \\
\hline Yes & $62(19.1 \%)$ & $263(80.9 \%)$ & 0.308 & $0.142-0.668$ & $0.002^{*}$ \\
\hline No & $13(43.3 \%)$ & $17(56.7 \%)$ & & & \\
\hline
\end{tabular}

*Significant findings.

\section{Discussion}

\subsection{Prevalence of Cervical Cancer Screening}

In this study, findings revealed that (21.1\%) of the respondents had ever screened for cervical cancer. Despite the low proportion of females who had screened for cervical cancer, it is still in agreement with data from Universities in other developing countries. The uptake of cervical cancer screening was reported to be 27.5\% in Botswana [8] 15\% in South Africa [12] 8\% [16] and 5.2\% in Nigeria [17] coinciding with that from the current study. The analogy could be due to the fact that the respondents were university students and majority had awareness about cervical cancer and cervical cancer screening. The possession of information by the participants which could be the main reason for the similar uptake rate of cervical cancer screening. In spite of the truth held by the above information, it is still lower than expected considering the increasing prevalence of the disease.

The level of uptake found was relatively similar to what was showed in some other earlier studies conducted in the same district as the current study, 29\% [10]. The 2015 study was done at a Reproductive Health Center that offers cervical cancer screening at no cost with the majority of the participants having characteristics like married and sexually active which was not the case with the present study. Additionally, the 2006's study findings could have been due to fact that the all participants were in the medical profession.

On the other hand, in the current study the prevalence of cervical cancer 
Table 7. Multiple logistic regression of background factors and cervical cancer screening.

\begin{tabular}{|c|c|c|c|}
\hline Variable & OR & $95 \% \mathrm{CI}$ & P-value \\
\hline \multicolumn{4}{|l|}{ Marital status } \\
\hline Married & 3.126 & $1.594-6.130$ & $0.001^{*}$ \\
\hline \multicolumn{4}{|l|}{ single } \\
\hline \multicolumn{4}{|l|}{ Year of study } \\
\hline$\leq$ Year 2 & 2.235 & $1.173-4.261$ & $0.015^{\star}$ \\
\hline \multicolumn{4}{|l|}{$>$ Year 2} \\
\hline \multicolumn{4}{|l|}{ Religion } \\
\hline Christian & 0.798 & $0.431-1.480$ & 0.475 \\
\hline \multicolumn{4}{|l|}{ Non-Christian } \\
\hline \multicolumn{4}{|c|}{ Current number of sexual } \\
\hline \multicolumn{4}{|l|}{ partners } \\
\hline One & 2.146 & $1.128-4.084$ & 0.20 \\
\hline \multicolumn{4}{|l|}{ multiple } \\
\hline \multicolumn{4}{|c|}{ Willingness to screen in the } \\
\hline \multicolumn{4}{|l|}{ future } \\
\hline Yes & 4.646 & $1.610-13.406$ & 0.05 \\
\hline \multicolumn{4}{|l|}{ No } \\
\hline \multicolumn{4}{|l|}{ Family planning use } \\
\hline Yes & 0.298 & $0.82-1.087$ & 0.067 \\
\hline \multicolumn{4}{|l|}{ No } \\
\hline \multicolumn{4}{|l|}{ Age of first sexual } \\
\hline \multicolumn{4}{|l|}{ intercourse } \\
\hline$\leq 16$ years & 0.656 & $0.344-1.253$ & 0.05 \\
\hline$>16$ years & & & \\
\hline
\end{tabular}

*Significant findings.

screening $(21.1 \%)$ was higher than that reveled in studies done in the other regions of the Uganda that showed findings of 4.8\% [11]. This discrepancy was due to the fact that the previous studies were done in rural regions were health system is poorly developed. This low level of screening in the other regions of the country is similar with the 5 -year screening prevalence for developing countries estimated by WHO 5\% [18] and in close agreement with a prevalence of 6\% reported by a Kenyan [19] and Tanzanian study [20]. Certainly, this relatively higher prevalence in this current study could have been attributed to the higher level of education of the participants and urban stay where facilities that offer cervical cancer screening are most concentrated and some screening facilities are in close vicinity with the university conversely to the above studies.

Cervical cancer screening uptake rate has been reported to be much higher in developed countries with over $80 \%$ in United States [14] and Netherlands [21], $76 \%$ in Canada [22] and above average (54.7\%) in Japan [23] in another study. 
This disparity may be due to the study design study setting and population characteristics. Also, that people in the developed world have more access to improved health care services than those in developing countries.

The low proportion of cervical cancer screening in present study leads to late diagnosis and poor prognosis of the disease as medical interventions are rendered unnecessary in the late stages of the disease. This increases the morbidity and mortality of females due to cervical cancer a preventable and curable disease when diagnosed early.

\subsection{Background Factors}

The background characteristics of the respondents are necessary in contextualizing the study. At multivariate analysis only Married status and year of study were significant, with the former having a $\mathrm{p}$-value of $(\mathrm{p}=0.001)$. This corresponds to what was discovered in a Nigerian study where over $18 \%$ of the married people had screened for cervical cancer [24]. This could be explained by the fact that perhaps respondents in the current study had good marital supportive relationships including in the field of health. Conversely, another study done concludes that husband's support does not have significant relationship to the behavior of using IVA screening implying that marriage has no significance with cervical cancer screening [8]. At the same time reproductive health programs recommend encouragement of male participation in reproductive health issues [19] the other hand participants who are married could perceive themselves high at risk as explained by a study in Ethiopia where HPV infection was the commonest STI in this population [25].

According to the current study, year of study; syear 2 was significant $(\mathrm{p}=$ 0.015). This could be because year 1 and year 2 students are a little less occupied and hence are more likely to participate more in health-related seeking behavior like cervical cancer screening more than other years. This implies that even students in other years should also be encouraged to participate in screening so as to increase the overall cervical cancer screening among University students.

\subsection{Facilitators to Cervical Cancer Screening}

The facilitators to cervical cancer screening found in this study included; access to free cervical cancer screening services, affordability of screening services, adequate knowledge about cervical cancer screening, youth friendly screening services, gender sensitive screening services, advice from a friend, family or physician among others. These reflect areas in which interventions can be developed to enhance cervical cancer screening uptake among University undergraduate students.

In this study, $61 \%$ of the women who screened agreed that access to free cervical cancer screening services promotes screening uptake. This corresponds to a study in rural Uganda that found that women who accessed reproductive health care from government facilities were more likely to have been screened for cervical cancer when compared to their counterparts at private facilities on biva- 
riate analysis. This could be due to the fact that cervical cancer screening service is free at the government health facilities that offer it unlike the private ones [11]. In another study [26], women with lower socioeconomic status were found to be much less likely to undergo the freely available cancer screening services. This could be due to the fact that both studies were carried in the same country which is a developing one in which the people have a low-income status. This underscores the importance of just setting up cervical cancer screening facilities as the cost of the screening also affects its uptake and also socio related factors. Therefore, to escalate the screening uptake in relation to this facilitator, free or subsidized cervical cancer screening services should be made readily available to women so as to expand the service.

Also critical is the need to increase access to free cervical cancer screening services within community to address health system challenges such as long distances to health facilities and transport costs. To achieve this in a developing country perspective, there is need to adopt outreach model of service delivery where screening services are extended to the citizens regularly while building capacity at even lower health centers like University hospitals. Integration of cervicalcancer screening services with others accessed by young women such as family planning, HIV/AIDS testing sessions and vaccinations.

In the present study over $64 \%$ agreed that getting advice about cervical cancer screening from a friend, family or physician facilitated their screening uptake. This is also reflected in another study that assessed structural and sociocultural factors associated with cervical cancer screening among HIV-infected African American women [27]. Additionally, another study has shown that women's decisions to screen are influenced by experiences of their friends or peers [11]. This overrates the importance of social influence in promoting cervical cancer screening. Social influence is a process where people directly or indirectly influence thoughts, feelings and action of others. In contrast however, another study concluded that husband and peer support does not have significant relationship to the behavior of cervical cancer screening uptake [27]. Never the less support can in one way or another influence screening uptake. Therefore, husbands and fellow women should be encouraged to advice their women and friends respectively to screen for cervical cancer.

Above the average (63\%) of all those who screened agreed that having adequate knowledge about cervical cancer screening influenced their screening. This correlated with previous studies done [28] where adequate knowledge on cervical cancer screening was affiliated to greater screening behavior. Likewise, a study among Medical students in China portrayed that $80 \%$ of the students believed that cervical cancer screening prevents cervical cancer and thus were more likely to uptake screening [29]. Additionally in another study in South Africa shows that on Pearson correlation analysis, cervical cancer knowledge had a significantly negative relationship with barriers to cervical cancer screening [30]. A previous study had cited lack of knowledge and awareness about the risk factors of cervical cancer as important factors impacting screening uptake [31]. Educa- 
tion on cervical screening through the mass media and health talks in delivering health care are imperative to informing women about cervical cancer and the facilities available for them. The media also needs to play a more active role in the campaign against cancer. This is likely to increase screening among females in Universities and the country at large.

\subsection{Barriers to Cervical Cancer Screening}

The present study showed that the participants perceived several barriers to undergoing a cervical cancer screening test. These included; fear of a bad result, feeling uncomfortable while undressing themselves before male health workers, low risk perception, financial constraints, fear of pain, limited time to go for cervical cancer screening due to the busy university schedule in correlation with a study in Cameroon (Edie et al., 2015). Many of the respondents didn't screen because they were afraid of a bad result (81\%). This finding is in line with a qualitative study conducted among Ugandan women in the Eastern region of the country where women feared the outcome of test results.

Also noted in that same study was the fact that women were feeling uncomfortable undressing themselves before health workers especially if they were male [11]. This is consistent with what was revealed in the current study where (49\%) were feeling ashamed to lie on a gynecological table for the cervical cancer screening test and $47 \%$ felt embarrassed especially if the physician was male.

Modesty and embarrassment were reported frequently as barriers for cervical cancer screening programs among African women in different countries $(\mathrm{Bu}-$ kirwa et al., 2015) and (Natasha, 2017) most prefer a female doctor. Equally important is the increased cervical cancer screening uptake (29\%) in Ugandan study where female nurse midwives conducted the screening [10]. This disparity in screening uptake in relation to the current study could have been be associated with African culture and norms that have specific traditions and lifestyles that shape women's actions, behaviors, health practices, beliefs, expectations, gender roles, and self-care. These practices therefore, may influence a woman's decision not to have a physical examination or other healthcare interventions if the health provider is a male regardless of the severity of the health conditions. To address this barrier, there should be an increment in the number of female nurses who manage women's health clinics so as to alleviate their anxiety and discomfort during screening.

In the present study, (53\%) female students perceived themselves to have a low risk perception of getting cervical cancer. Hence, this belief was a barrier to acquiring a screening test as stated by more than half of the students who didn't screen. This finding is in concordance with a cross-sectional study conducted in the University of Botswana (UB) amongst female students which reported that over $83 \%$ didn't see the need for cervical cancer screening as they felt that they weren't at risk of contracting the disease (Tapera et al., 2017) same as a study in Bhutan (Dhendup \& Tshering, 2014). These findings is also in synchrony with a theory based study among University students in South Africa, which reported 
that the cervical cancer screening (Pap smear) test uptake was directly associated with higher scores of susceptibilities, seriousness, and benefits, and was indirectly associated with perceived barriers to undergoing the test (Hoque et al., 2014). This strongly suggests that female undergraduates are poorly informed about the means and benefits of cancer screening. Young girls need to know that cancer screening helps to detect disease before manifestation of symptoms so that prompt treatment could be initiated which would prevent cancer This is however in contrast to the findings in a population based study done in London were majority of the study participants didn't endorse the low risk perception as a barrier for screening uptake [7] This disparity could be explained by the fact that the current study was only in University students aged mostly 21 - 25 years and single while the former study's participants were from $26-64$ years and most were married. Cervical cancer awareness and prevention programs should continually seek to influence women's perceptions about cervical cancer and screening many studies, just like in this study (50\%) have also shown that financial concerns may act as barriers to undergoing a cervical cancer screening especially if the women have to pay for the test. More than half of the women (61.2\%) in a similar study done among Nigerian women to assess their barriers for the screen uptake showed that several participants who had not been screened for cervical cancer were willing to be screened if a free screening test was provided. Additionally the high cost of screening in a study conducted at Moi teaching and referral hospital in Kenya, where about $11.4 \%$ of the participants reported lack of finances as a barrier [31] also in study in Masaka [32] and Nigeria [7]. This is could be explained by the low financial background of the current study's respondents as most are full time students and thus are not employed. A screening program among such a population is thus more likely to be successful if it is provided at no or low cost to the participants.

The fear of pain related to the screening test perceived by over $52 \%$ of the study respondents was also a barrier to screening uptake reflected in the study. This correlated with what was revealed in a systematic scoping review study done among immigrant women in Canada [33].

This similarity may have arisen due to the low knowledge about the screening procedure among the participants leading to the pain perception. The fear of pain anticipated in the screening test procedure may prevent some women from undergoing the test. Therefore, explaining the procedure may reduce anxiety and improve the uptake in women.

In this study, it was found that over $62 \%$ of those who hadn't screened reported that limited time to go for cervical cancer screening due to the busy university schedule was also a barrier to screening uptake. This finding is only slightly higher than that reported in a study in Sweden were $51.4 \%$ reported not being able to take time off work as the reason for non-compliance to cervical cancer screening [34]. Further still, a qualitative study in England among ethnic minority women assessing barriers to screening uptake revealed lack of time to attend and being too busy as common explanations given for the poor screening 
uptake [35].

Still noted among the barriers in this current study was the fact that $72 \%$ of the participants agreed that there was no health facility close to the university that offers cervical cancer screening services. Noteworthy, is the fact that in another study that assessed uptake and correlates of cervical cancer screening among HIV-infected women attending HIV care in Uganda; distance to health facility was found to be significant on bivariate analysis. Proximity to a clinic is also an important consideration as close proximity enables women to attend using a mode of transport with zero cost.

In this study, less than a half (41\%) of the respondents reported that they were discouraged to go for screening because of the long waiting time at the facility. Similar findings were also reported in a another Ugandan study where respondents reported that long waiting time at the cervical cancer screening facility was a disincentives to their screening uptake [9]. This coherence could be affiliated to the similarity in some study population characteristics. This implies that if cervical cancer screening services are scaled up and the identified barriers addressed, more women would access screening.

\section{Conclusions}

This study showed that the prevalence of cervical cancer screening among the literate population of female undergraduate students of Makerere University is relatively low (21.1\%). The likely reason for this could be because students do not perceive themselves to be susceptible to cancer so the lesser the likelihood of engaging in preventive behaviors.

Access to free cervical cancer screening services, adequate knowledge about cervical cancer screening and advice from a friend, family or physician among others were some of the facilitators from the current study. The reported barriers to screening were fear of bad result, low risk perception and fear of embarrassment were a part of the barriers elicited in this study. To improve cervical cancer screening, effort should be focused on reducing identified barriers and enhancing facilitators to cervical cancer screening.

\subsection{Limitations}

The study tool was a self-administered and is therefore open to the usual reporting biases inherent in such study.

The study population included young university students, and this has implications for the generalizability of the findings to less educated or older women.

The cross-sectional nature of the survey means causal inferences cannot be made from the results reported.

Some of the questions in the questionnaire were sensitive which could have led to under reporting.

\subsection{Recommendations}

There is a critical need for university-based cancer education campaign on cer- 
vical cancer and the benefits of screening. Screening services should be integrated into the existing university medical services. The knowledge of common public health problems should be built into courses undertaken by undergraduates in non-health related fields.

The University should also organize medical camps at collage level so as to increase the accessibility of cervical cancer screening services among University students.

The government of Uganda through the ministry of health should establish free and youth friendly cervical cancer screening services in all government hospitals including University hospitals so as to boost the coverage of screening uptake among young people in different parts of the country.

\section{Conflicts of Interest}

The authors declare no conflicts of interest regarding the publication of this paper.

\section{References}

[1] Siegel, R.L., Miller, K.D. and Jemal, A. (2016) Cancer Statistics, 2016. A Cancer Journal for Clinicians, 66, 7-30. https://doi.org/10.3322/caac.21332

[2] Black, E., Hyslop, F. and Richmond, R. (2019) Barriers and Facilitators to Uptake of Cervical Cancer Screening among Women in Uganda: A Systematic Review. BMC Women's Health, 19, Article No. 108. https://doi.org/10.1186/s12905-019-0809-Z

[3] Bukirwa, A., et al. (2015) Motivations and Barriers to Cervical Cancer Screening among HIV Infected Women in HIV Care: A Qualitative Study. BMC Women's Health, 15, Article No. 82. https://doi.org/10.1186/s12905-015-0243-9

[4] Dhendup, T. and Tshering, P. (2014) Cervical Cancer Knowledge and Screening Behaviors among Female University Graduates of Year 2012 Attending National Graduate Orientation Program, Bhutan. BMC Women's Health, 14, Article No. 44. https://doi.org/10.1186/1472-6874-14-44

[5] Ebu, N.I., et al. (2015) Knowledge, Practice and Barriers toward Cervical Cancer Screening in Elmina, Southern Ghana. International Journal of Women's Health, 7, 31-39. https://doi.org/10.2147/IJWH.S71797

[6] Ekane, G.E.H., et al. (2015) Pap Smear Screening, the Way forward for Prevention of Cervical Cancer? A Community Based Study in the Buea Health District, Cameroon. Open Journal of Obstetrics and Gynecology, 5, 226-233. https://doi.org/10.4236/ojog.2015.54033

[7] Aniebue, P. and Aniebue, U. (2010) Awareness and Practice of Cervical Cancer Screening among Female Undergraduate Students in a Nigerian University. Journal of Cancer Education, 25, 106-108. https://doi.org/10.1007/s13187-009-0023-Z

[8] Tapera, R., et al. (2017) Knowledge and Attitudes towards Cervical Cancer Screening amongst University of Botswana Female Students. Asian Pacific Journal of Cancer Prevention: APJCP, 18, 2445-2450.

[9] Mukama, T., et al. (2017) Women's Knowledge and Attitudes towards Cervical Cancer Prevention: A Cross Sectional Study in Eastern Uganda. BMC Women's Health, 17, Article No. 9. https://doi.org/10.1186/s12905-017-0365-3

[10] Osingada, C.P., et al. (2015) Determinants of Uptake of Cervical Cancer Screening 
Services at a No-Cost Reproductive Health Clinic Managed by Nurse-Midwives. Cancer Nursing, 38, 177-184. https://doi.org/10.1097/NCC.0000000000000156

[11] Ndejjo, R., et al. (2017) Knowledge, Facilitators and Barriers to Cervical Cancer Screening among Women in Uganda: A Qualitative Study. BMJ Open, 7, e016282. https://doi.org/10.1136/bmjopen-2017-016282

[12] Oberlin, A.M., Pasipamire, T. and Chibwesha, C.J. (2019) Exploring Women's Preferences for HPV-Based Cervical Cancer Screening in South Africa. International Journal of Gynecology \& Obstetrics, 146, 192-199. https://doi.org/10.1002/ijgo.12869

[13] Nakisige, C., et al. (2020) Integrated Cervical Cancer Screening in Mayuge District Uganda (ASPIRE Mayuge): A Pragmatic Sequential Cluster Randomized Trial Protocol. BMC Public Health, 20, Article No. 142. https://doi.org/10.1186/s12889-020-8216-9

[14] Smith, R.A., et al. (2018) Cancer Screening in the United States, 2018: A Review of Current American Cancer Society Guidelines and Current Issues in Cancer Screening. A Cancer Journal for Clinicians, 68, 297-316.

https://doi.org/10.3322/caac.21446

[15] Aldohaian, A.I., Alshammari, S.A. and Arafah, D.M. (2019) Using the Health Belief Model to Assess Beliefs and Behaviors Regarding Cervical Cancer Screening among Saudi Women: A Cross-Sectional Observational Study. BMC Women's Health, 19, Article No. 6. https://doi.org/10.1186/s12905-018-0701-2

[16] Phaswana-Mafuya, N. and Peltzer, K. (2018) Breast and Cervical Cancer Screening Prevalence and Associated Factors among Women in the South African General Population. Asian Pacific Journal of Cancer Prevention: APJCP, 19, 1465-1470.

[17] Chigbu, C.O., et al. (2017) The Impact of Community Health Educators on Uptake of Cervical and Breast Cancer Prevention Services in Nigeria. International Journal of Gynecology \& Obstetrics, 137, 319-324. https://doi.org/10.1002/ijgo.12150

[18] Tsikouras, P., et al. (2016) Cervical Cancer: Screening, Diagnosis and Staging. Journal of BUON, 21, 320-325.

[19] Sudenga, S.L., et al. (2013) Knowledge, Attitudes, Practices and Perceived Risk of Cervical Cancer among Kenyan Women: Brief Report. International Journal of $G y-$ necologic Cancer, 23, 895-899. https://doi.org/10.1097/IGC.0b013e31828e425c

[20] Plotkin, M., et al. (2014) Integrating HIV Testing into Cervical Cancer Screening in Tanzania: An Analysis of Routine Service Delivery Statistics. BMC Women's Health, 14, Article No. 120. https://doi.org/10.1186/1472-6874-14-120

[21] Habbema, D., De Kok, I.M. and Brown, M.L. (2012) Cervical Cancer Screening in the United States and the Netherlands: A Tale of TWO countries. The Milbank Quarterly, 90, 5-37. https://doi.org/10.1111/j.1468-0009.2011.00652.x

[22] Lofters, A.K., et al. (2011) Predictors of Low Cervical Cancer Screening among Immigrant Women in Ontario, Canada. BMC Women's Health, 11, Article No. 20. https://doi.org/10.1186/1472-6874-11-20

[23] Kurokawa, T., et al. (2018) The Ideal Strategy for Cervical Cancer Screening in Japan: Result from the Fukui Cervical Cancer Screening Study. Cytopathology, 29, 361-367. https://doi.org/10.1111/cyt.12576

[24] Idowu, A., et al. (2016) Determinants of Cervical Cancer Screening Uptake among Women in Ilorin, North Central Nigeria: A Community-Based Study. Journal of Cancer Epidemiology, 2016, Article ID: 6469240.

https://doi.org/10.1155/2016/6469240 
[25] Getachew, S., et al. (2019) Cervical Cancer Screening Knowledge and Barriers among Women in Addis Ababa, Ethiopia. PloS ONE, 14, e0216522. https://doi.org/10.1371/journal.pone.0216522

[26] Shin, D.W., et al. (2018) Disparities in Cervical Cancer Screening among Women with Disabilities: A National Database Study in South Korea. Journal of Clinical Oncology, 36, 2778-2786. https://doi.org/10.1200/JCO.2018.77.7912

[27] Nakisige, C., Schwartz, M. and Ndira, A.O. (2017) Cervical Cancer Screening and Treatment in Uganda. Gynecologic Oncology Reports, 20, 37-40. https://doi.org/10.1016/j.gore.2017.01.009

[28] Roik, E.E., et al. (2017) Do Cervical Cancer Patients Diagnosed with Opportunistic Screening Live Longer? An Arkhangelsk Cancer Registry Study. International Journal of Environmental Research and Public Health, 14, 1500.

https://doi.org/10.3390/ijerph14121500

[29] Pan, X.-F., et al. (2014) Acceptability and Correlates of Primary and Secondary Prevention of Cervical Cancer among Medical Students in Southwest China: Implications for Cancer Education. PLoS ONE, 9, e110353.

https://doi.org/10.1371/journal.pone.0110353

[30] Hoque, M.E., et al. (2014) Cervical Cancer Screening among University Students in South Africa: A Theory Based Study. PloS ONE, 9, e111557. https://doi.org/10.1371/journal.pone.0111557

[31] Were, E., Nyaberi, Z. and Buziba, N. (2011) Perceptions of Risk and Barriers to Cervical Cancer Screening at Moi Teaching and Referral Hospital (MTRH), Eldoret, Kenya. African Health Sciences, 11, 58-64.

[32] Twinomujuni, C., Nuwaha, F. and Babirye, J.N. (2015) Understanding the Low Level of Cervical Cancer Screening in Masaka Uganda Using the ASE Model: A Community-Based Survey. PloS ONE, 10, e0128498. https://doi.org/10.1371/journal.pone.0128498

[33] Ferdous, M., et al. (2018) Barriers to Cervical Cancer Screening Faced by Immigrant Women in Canada: A Systematic Scoping Review. BMC Women's Health, 18, Article No. 165. https://doi.org/10.1186/s12905-018-0654-5

[34] Osterman, L. and Manns, K. (2019) Cervixcancerochcellprovtagning: Enlitteraturöversiktförattbelysakvinnorsattityder till cellprovtagningurettglobaltperspektiv.

[35] Vora, K., et al. (2020) Community Level Barriers for Cervical Cancer Screening in Marginalized Population. International Journal of Reproduction Contraception Obstetrics and Gynecology, 9, 5006-5011. 